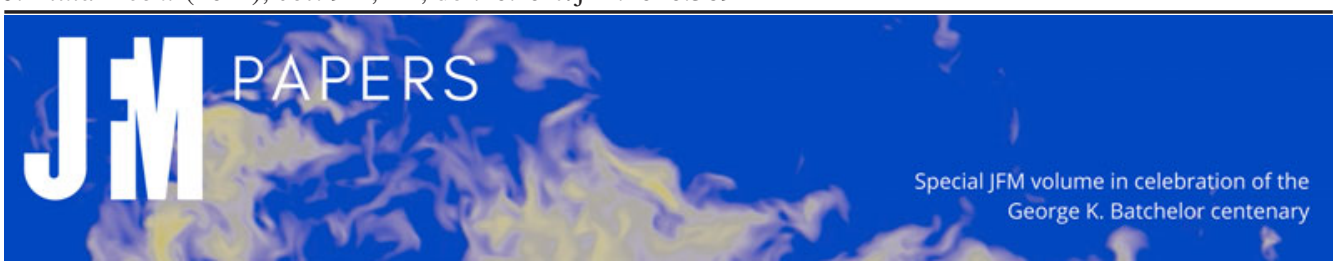

\title{
George Batchelor and the founding of Euromech
}

\author{
Patrick Huerre $\dagger$ \\ Laboratoire d'Hydrodynamique - LadHyX, CNRS - Ecole Polytechnique, Institut Polytechnique de Paris, \\ F-91128 Palaiseau, France
}

(Received 20 March 2020; revised 20 May 2020; accepted 7 July 2020)

This article shows how George Batchelor, in close collaboration with Dietrich Küchemann, succeeded in founding Euromech, the European Mechanics Committee, in the sixties during the rise of the 'Cold War'. It is argued that the initial success of Euromech was due to the organisation of Euromech Colloquia, i.e. meetings of at most 50 scientists, focussing on a sufficiently specialised topic and leaving ample time for informal discussions. The maturation of Euromech into the European Mechanics Society in the nineties is then analysed. This transition was in part made necessary by the creation of five series of large European Conferences in Fluid and Solid Mechanics, Turbulence, Nonlinear Oscillations and Mechanics of Materials. The collective action of George Batchelor and a few outstanding European scientists is brought to light.

Key words: turbulent flows

\section{Introduction}

Over the last fifty years the European Mechanics Society, commonly referred to as Euromech, has succeeded in bringing together the community of European scientists engaged in fundamental and applied research in Mechanics. This process came about through the decisive steps and initiatives taken collectively by a few outstanding personalities among whom the Australian-born George Batchelor emerged as a natural benevolent leader. This paper is a short account of the 'story' of Euromech by one of its former Presidents from 2003 to 2012, who knows the Society as it has developed in the last twenty years, but did not live through the 'formative period' preceding the year 2000. A very comprehensive history of the Society until 2000 (Fernholz 2010) proved to be an extremely valuable source of information for the author of the present much shorter contribution. Hans Fernholz was very much involved in Euromech almost right from the beginning in 1965 for Colloquium 1 as the young assistant of Professor Rudolf Wille at the Hermann Föttinger Institut in Berlin. He later served as a member and Secretary of

$\dagger$ Email address for correspondence: huerre@ladhyx.polytechnique.fr 


\section{P. Huerre}

(a)

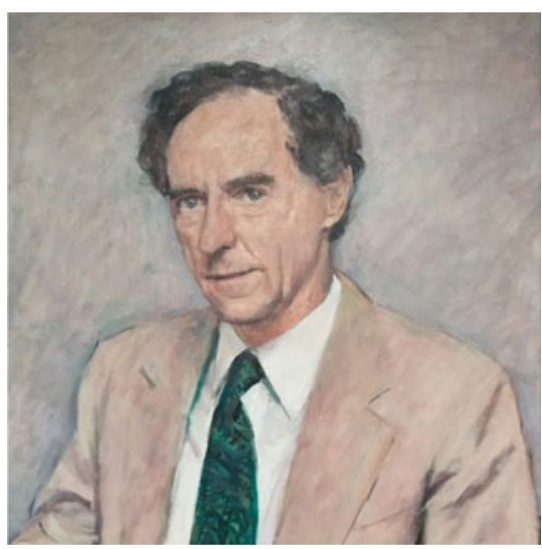

(b)

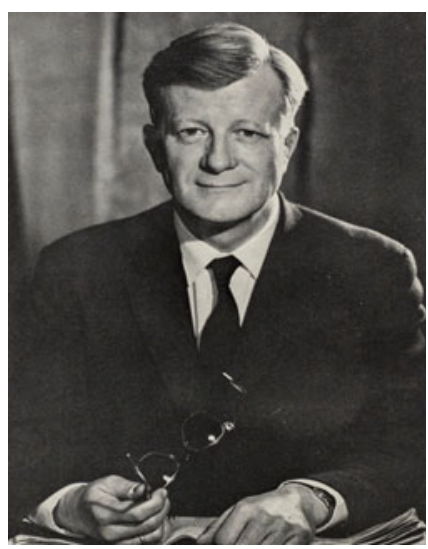

Figure 1. The founders of Euromech. (a) George Batchelor (1920-2000) () Mark Hallworth. Reproduced with permission. (b) Dietrich Küchemann (1911-1976) @ Godfrey Argent Studio. Image reproduced with permission from Royal Society Publishing.

the European Mechanics Committee, and finally as President and Vice-President of the European Mechanics Society.

In the immediate post Second World War period, scientists in many European countries were understandably concerned by the establishment of new channels of communication and cooperation within the confines of their own national boundaries. It is only in the early and mid sixties that they began to consider exchanging scientific ideas and organising conferences on the much larger European scale. Any effort in that direction would of course have to face the division between Western and Eastern Europe brought about by the 'Cold War'.

\section{The founders of Euromech}

It is in this general setting that two exceptional fluid dynamicists, George Batchelor (figure 1a) and Dietrich Küchemann (figure 1b), first had the good fortune of meeting each other, and second, shared the compelling need for European cooperation in the Mechanical Sciences. They may indeed be regarded as the two co-founders of Euromech.

George Batchelor (1920-2000) moved from Australia to the United Kingdom in 1945, to work with G.I. Taylor. In the early sixties, at a time when European collaboration became of growing concern, he was internationally renowned for his accomplishments in the field of turbulence. He knew well the Fluid and Solid Mechanics communities in Western and Eastern Europe as well as in the USA and, for several years, he had been a member of the influential Congress committee of the International Union of Theoretical and Applied Mechanics (IUTAM). These extensive contacts would prove to be very important in the initial stages leading to the creation of Euromech. Foremost, he was the founder, in 1959, of the respected Department of Applied Mathematics and Theoretical Physics (DAMTP) at the University of Cambridge. In 1956 he had also founded the Journal of Fluid Mechanics which was already considered as the pre-eminent means of publication in the field. G. Batchelor was often a participant in the biennial 'East meets West' fluid mechanics conferences organised in Poland by Wladeck Fiszdon (Warsaw). As such, he knew many colleagues from Eastern Europe and from the Soviet Union, a great asset in building bridges across the whole of Europe.

Dietrich Küchemann (1911-1976) studied for his Doctorate in Göttingen under the supervision of Ludwig Prandtl. Until 1946, he was engaged in High Speed Aerodynamics 


\section{G. Batchelor and the founding of Euromech}

research at the famous Aerodynamische Versuchsanstalt (AVA), also in Göttingen. He then moved to the UK to join the Royal Aircraft Establishment (RAE) in Farnborough to continue his work in Aerodynamics. It is remarkable that his book entitled 'The Aerodynamic Design of Aircraft' (Küchemann 2013) has continued to be published since his early death in 1976. Apparently, his colleagues at RAE referred to his 'area-ruled' fuselage as 'Küchemann's Coke bottle'. According to Fernholz (2010), Dietrich Küchemann was unassuming and very much a European man and a citizen of the World (Fernholz 2010). He ultimately became Chief Scientific Officer at RAE and a Visiting Professor at Imperial College. George Batchelor, the renowned and greatly influential scholar and Dietrich Küchemann, the brilliant modest Engineer in the great German tradition were endowed with very complementary talents which were essential in the founding phase of Euromech. In the 1960s, both men had definitely reached full maturity in their scientific careers.

\section{Towards Euromech - the European Mechanics Committee}

According to Fernholz (2010), the first soundings alluding to the need for closer scientific exchanges in Europe seem to have been made by Klaus Oswatitsch, a respected Austrian researcher in Gas Dynamics who had also worked during the war with Ludwig Prandtl in Göttingen. In the fifties, Oswatitsch became the director of the newly founded Deutsche Versuchsanstalt für Luftfahrt (DVL) in Aachen and he happened to meet Küchemann at the Symposium Transonicum meeting of 1962. On that occasion Oswatitsch mentioned to Küchemann 'that he would very much like to find a way to bring together more closely people working in fluid mechanics in Western Europe' (Fernholz 2010). The main idea was to hold informal meetings in order to discuss topics of common interest and to initiate personal contacts. Küchemann found the idea attractive and together they drafted a summary proposal for Fluid Mechanics Conferences in Western Europe which was then sent out to several colleagues for comments in 1963. Very favourable replies were received from James Lighthill (London), Paul Germain (Paris) and Brian Thwaites. The need for smaller meetings on specialised topics in fluid mechanics was repeatedly stressed.

A few months later in 1963, George Batchelor participated in the biennial Conference in Fluid Dynamics attended by European scientists from the East and the West and organised by Wladeck Fiszdon (Warsaw) in Poland. Both Batchelor and Fiszdon came to the conclusion that greater cooperation between Eastern and Western researchers was very desirable.

Highly supportive signals were also received from the Royal Society of London and IUTAM. So it is that on the occasion of the 12th International Congress of Theoretical and Applied Mechanics (12th ICTAM) held in Munich, 'twelve representatives from six countries met over lunch on 2nd September 1964, at the Künstlerhaus am Lenbachplatz, a pleasant venue (figure 2) for artistic and cultural events. All were very favourable to the idea (of research colloquia) and an Interim Committee for European Mechanics Colloquia (Euromech) was established, comprising all those present at this first meeting, with Batchelor acting as Chairman and Küchemann as Secretary of the Committee' (Fernholz 2010).

\section{Euromech colloquia}

The main features of a Euromech Colloquium were elegantly envisioned in a working document (Batchelor \& Küchemann 1964) that formed the basis for the discussions at the 1964 meeting in Munich. As many of the features are still relevant to this day, it is worth 


\section{P. Huerre}

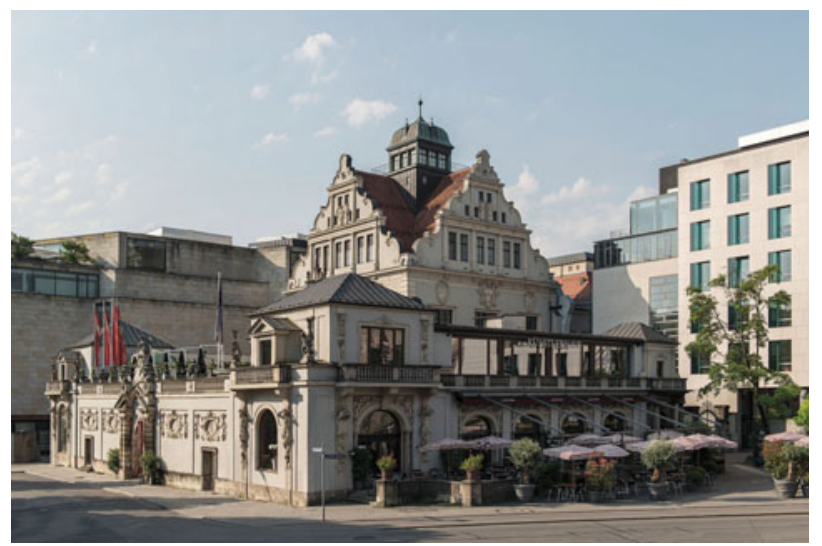

Figure 2. Künstlerhaus at the Lenbachplatz, Munich. Kmuc CC BY-SA 4.0, via Wikimedia Commons.

quoting a few passages: 'There seems to be a case for a less formal gathering, which we may conveniently term a Colloquium, on a level intermediate between those of the formal Symposium and the private visit. The subject matter to be discussed would either be more specialised than that generally chosen for a formal symposium, or at a less developed stage; the scope would be such that the participants, invited because they have something to contribute, can all be expected to follow the discussion fully. The Colloquium should restore the immediacy and directness of personal contact in lively and spontaneous debate on current work by people personally engaged on it, from which considerations of prestige are absent. The Colloquium should help to reduce the isolation of the working scientist which tends to result from the continual and rapid ramification of subjects, and it should lead him to notice aspects of his problem which he would otherwise have ignored (...)'.

The guidelines that emerged from this 'founders meeting' and that have proved to be most effective to hold a successful colloquium are the following: 'Live topic' in Fluid/Solid Mechanics sufficiently specialised; a maximum of 50 invited participants, selected for their own active work and not as representatives of organisations, with junior colleagues to be also solicited; a duration of 3-4 days; planning of plenty of time left for informal discussions and for knowing each other personally; no proceedings.

The first Euromech colloquium entitled 'The Coanda effect' was held on the 5th and 6th of April 1965, at the Technische Universität Berlin, under the chairmanship of Professor Rudolf Wille (figure 3). The event was organised in close collaboration with Dietrich Küchemann. There were 38 participants originating from 9 European countries. The detailed report written after the colloquium concluded as follows: 'It may justifiably be hoped that this first Euromech Colloquium at Berlin has initiated a series of working conferences which will benefit both the research scientist and the advancement of knowledge' (Fernholz 2010). The colloquium framework turned out to be highly successful, with approximately 10-15 colloquia supported each year and over 600 colloquia have been organised since 1965 .

\section{Euromech - the European Mechanics Committee (1964-1993): George Batchelor as Chairman (1964-1987)}

Until 1987, the proposals for colloquia were evaluated each year by the Euromech Colloquium Committee, more formally known as the European Mechanics Committee (EMC for short). In its steady-state configuration, the EMC was composed of about ten 


\section{G. Batchelor and the founding of Euromech}

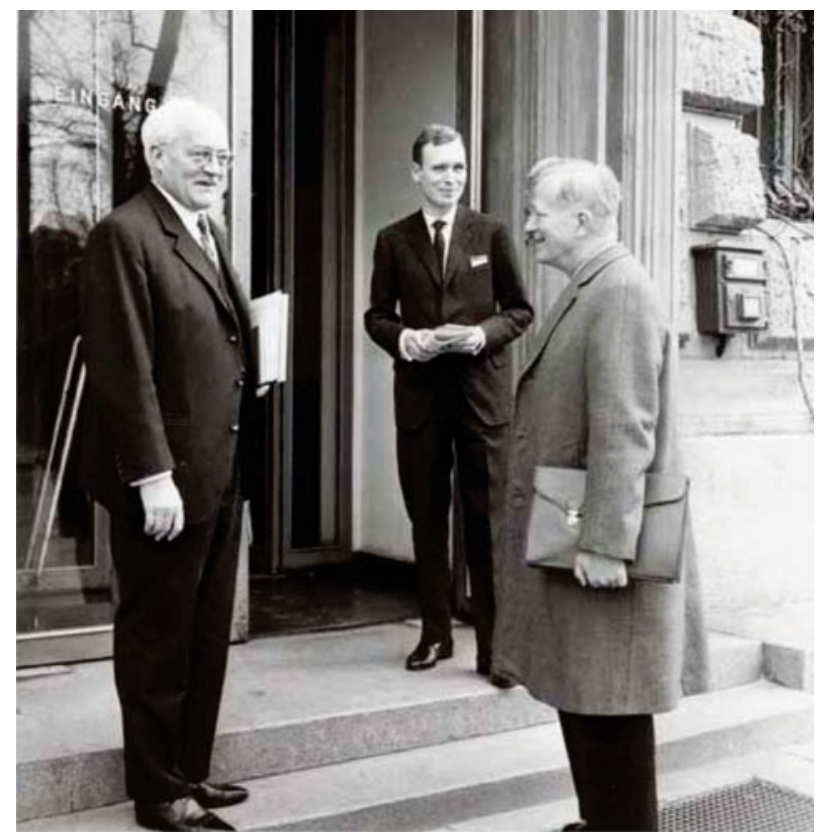

Figure 3. From left to right: Rudolf Wille, Hans Fernholz, Dietrich Küchemann, Euromech Colloquium 1, Berlin 1965. Reproduced with permission. Courtesy of the Hermann-Föttinger-Institute at TU Berlin.

co-opted scientists with diverse expertise in Fluid and later Solid Mechanics, originating from a variety of European countries. Dietrich Küchemann who played a crucial part in the establishment of Euromech had to resign from being Secretary in 1974 and died prematurely in 1976. Hans Fernholz (Berlin), who had been a committee member very early on, became his successor as Secretary (1975-1989), followed by Bengt Lundberg (1990-1993) from Lund. During George Batchelor's tenure as Chairman of the EMC, from 1964 to 1987, the annual meetings of EMC were firmly led according to his extremely rigorous standards. In his 'Recollections as a Euromech old-timer' (Appendix 1 in Fernholz 2010), Leen van Wijngaarden gives a vivid account of George's unique style in handling and organising the discussions: '(...) In that time George Batchelor was the omnipresent chairman. In inviting you to serve on the Euromech Colloquium Committee he made you feel that you were about to take part in one of the most important enterprises in your scientific life. You could not do less than giving your very best. There were until 1990 no Euromech Conferences to discuss, only the proposals for Euromech Colloquia. There were typically some 25-30 proposals from which eventually, depending of how many Hans Fernholz could handle in his administration, 12-15 were selected after two full days of thorough discussion of each of the proposals. In many of the obituaries of George Batchelor the meticulous way is described in which he treated each proposal, bringing the meeting to an end well into late Saturday afternoon. The start was on Thursday evening when the Committee gathered in a restaurant for dinner, late proposals were handed out, and the agenda for the coming two days was settled. After all this hard work, Saturday night was to relax. Most of the time the Committee was invited in their home by the host and his wife. I have the best recollections of excellent dinners and pleasant evenings. The atmosphere was always relaxed at those occasions and there was time for jokes and laughter (...)'. 


\section{P. Huerre}

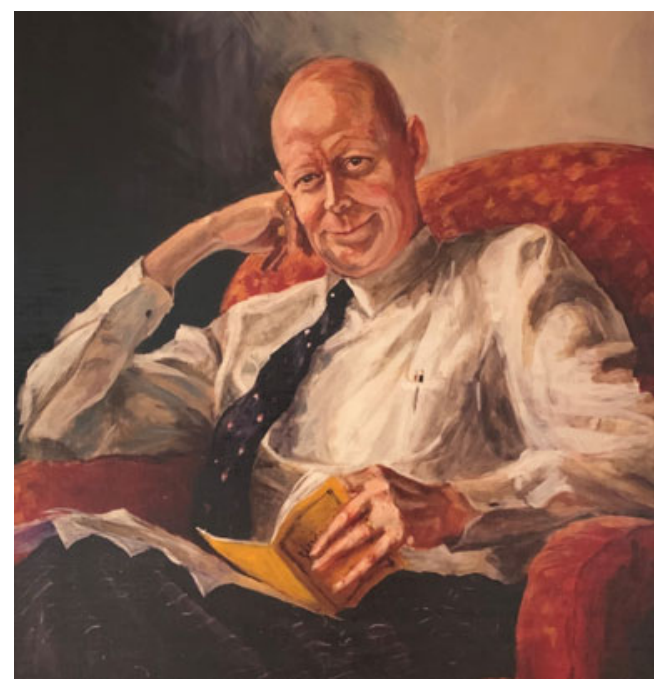

Figure 4. David Crighton (1942-2000).

6. The transition from the European Mechanics Committee (1964-1993) to the European Mechanics Society (1994-present)

Even though the selection and support of colloquia proved to be the hallmark of Euromech, by the mid eighties the European Mechanics Committee began to consider enlarging the scope of its activities via the organisation of several series of much larger European Conferences: originating from discussions between Egon Krause (Aachen) and Hans Fernholz (Berlin) the 1st European Turbulence Conference (ETC) was successfully held in Lyon in 1986 under the chairmanship of Geneviève Comte-Bellot and Jean Mathieu. Preparations were then made to set up a series of European Fluid Mechanics Conferences (1st EFMC in Cambridge in 1991) and a series of Solid Mechanics Conferences (1st ESMC in Munich in 1991). These initiatives led in turn to the necessary transformation of the European Mechanics Committee, in charge of Colloquia only, into the European Mechanics Society, in charge of Colloquia and ultimately of five series of European Conferences.

\section{From Chairman George Batchelor (1964-1987) to President David Crighton (1994-1997)}

During this transition period, the DAMTP at Cambridge very much remained at the helm of Euromech: at the 1987 annual Committee meeting George Batchelor announced that he wished to voluntarily resign from being Chairman of Euromech. David Crighton (figure 4) also at DAMTP, became his successor as Chairman of the Euromech Committee (1988-1993).

As reported by Fernholz (2010), during this Committee meeting in 1987 where Batchelor said he would like to resign, Leen van Wijngaarden who had stepped in as the temporary Chair, expressed his warmest thanks to George Batchelor for his 23 years of office. The Committee gave him a standing ovation and Batchelor's reply, sent as a letter to the Committee members, read: 'This is probably my last communication to you as Chairman of the Committee. I put down my Euromech pen with some regret, since helping our small organization to become a useful and respected agency of the Mechanics community in 


\section{G. Batchelor and the founding of Euromech}

Europe has been an interesting, pleasant and gratifying experience. I appreciate very much the kind words expressed at our last meeting, and want to thank you all for your unfailing support and co-operation. The fact that Euromech is in such good hands makes it easy to retire. And now over to David Crighton!'

George was no longer in charge but he remained strongly involved in Euromech activities and development. Together with David Crighton and Hans Fernholz, the Secretary of the Euromech Committee (1975-1989), they were the prime movers in this transformation phase of Euromech. George took the responsibility of drafting the 'terms of reference' and 'rules of procedure' for the new Society, the first three paragraphs (Fernholz 2010) reflecting Batchelor's typical 'straightforward' style: '(i) The function of the European Mechanics Council is to arrange meetings of scientists and engineers in Europe for the exchange of ideas and information about developments in theoretical, experimental, and applied mechanics. (ii) The meetings may be of different types, including both small closed colloquia on specialized topics and large open conferences on broad subjects. (iii) The meetings arranged by the Council should be characterized by simplicity, international friendship, and scientific effectiveness (...)'. The Statutes of the Society replaced these temporary documents as of 1994 and the transition to a bona fide Society was thereby completed. In his usual vigorous and friendly style, David Crighton, Chairman of the European Mechanics Committee (1988-1993), became in 1994 the first President of the newly established European Mechanics Society, and Hans Fernholz its first Secretary-General.

\section{European mechanics conferences}

The general format of European Mechanics Conferences, which is still pertinent today, was delineated by David Crighton in 1989 (Fernholz 2010): 'The general purpose of Euromech Conferences is to provide opportunities for scientists and engineers from all parts of Europe, East and West, to discuss current research (...)' Series of conferences are 'broad in scientific scope (...) and are expected to have a number of participants between 150 and 600 (...) The European Mechanics Council (...) delegates responsibility for the general planning and supervision of each series of conferences to a Standing Committee (of about 10 members) (...) Appointments to these committees are made by the Euromech Council (EMC) (...) It is a long-standing principle of the EMC that the cost of participation in a scientific meeting should be kept as low as possible (...)'.

There are currently five series of conferences:

(i) European Fluid Mechanics Conferences (EFMC): every 2 years, 13 EFMCs held so far.

(ii) European Solid Mechanics Conferences (ESMC): every 3 years, 10 ESMCs held so far.

(iii) European Turbulence Conferences (ETC): every 2 years, 17 ETCs held so far.

(iv) European Nonlinear Oscillations Conferences (ENOC): every 3 years, 10 ENOCs held so far.

(v) European Mechanics of Materials Conferences (EMMC): every 2 years, 17 EMMCs held so far.

After his resignation as Chairman of the Euromech Committee in 1987, George remained a regularly co-opted member of the Euromech Committee. From 1990 to 1994 he became the first Chairman of the Standing Committee in charge of supervising the EFMC series of conferences during its launching phase at the first EFMC in Cambridge in 1991. Likewise, as Chairman of the Standing Committee in charge of the ESMC series from 


\section{P. Huerre}

1991 to 1994, Werner Schiehlen (Stuttgart) played a pivotal role in the launching phase of Solid Mechanics conferences.

\section{George Batchelor's late years (1994-2000)}

In 1993 G.K. Batchelor noted that in resigning from the Euromech Council he would also resign as Chairman of the EFMC Standing Committee (Fernholz 2010). It is therefore on December 31st 1994 that George's involvement in Euromech came to an end, after 31 years of dedicated service to the community of European scientists in Mechanics. He spent his last years in the caring and affectionate company of his colleagues at DAMTP. He passed away on March 30th, 2000.

In 1997 David Crighton fell ill and had to relinquish the Presidency. As mentioned in $\S 1$, Hans Fernholz had been closely associated with the life of Euromech since its inception in the sixties. In the eyes of the Council, his tactfulness, balanced judgment and extensive knowledge of Euromech made him the natural successor (1998-2002) of David Crighton throughout this difficult period. It is a sad coincidence that David, who benefitted from the special attention of his peers during his illness, wrote a moving obituary of George one month before his own death on April 12th, 2000. This eulogy was read by Tim Pedley (Cambridge) at the Euromech Council held in Vienna in April 2000 (Fernholz 2010).

\section{Euromech awards}

Among the many accomplishments of Hans Fernholz as President (1998-2002), one should particularly single out the introduction of several types of Euromech distinctions.

In 1998, the Council created the status of Honorary Member of the Euromech Society. George Batchelor and Wladeck Fiszdon (Warsaw) were the first two recipients of this award which honours esteemed colleagues for exceptional service to Euromech and to the development of Mechanics in Europe. There are currently ten Honorary Members of the Society.

In 2002, the Society introduced the Euromech Fluid Mechanics and Solid Mechanics Prizes to members of the Mechanics community for their distinguished life-time contributions to Mechanics with a monetary prize of 5000 Euros each. They were awarded for the first time in 2003 at the European Fluid and Solid Mechanics Conferences. On this occasion, the recipient is invited to give a Prize lecture. A nomination may be submitted by any member of the Mechanics community. The first Fluid Mechanics Prize was awarded to Keith Moffatt (Cambridge) and the first Solid Mechanics Prize to Franz Ziegler (Vienna). There are currently 8 recipients of the EUROMECH Prize in Fluid Mechanics and 7 in Solid Mechanics.

In 2005, the Council further created the status of Euromech Fellow to recognise members who have contributed significantly to the advancement of Mechanics and related fields. Election to the status of Fellow of Euromech - The European Mechanics Society takes place in the year of the appropriate European Conference, EFMC or ESMC respectively. The first Euromech Fellows in Fluid Mechanics were elected in 2006: Bruno Eckhardt (Marburg), Jacques Magnaudet (Toulouse), Grae Worster (Cambridge). The first Euromech Fellows in Solid Mechanics were also elected in the same year: Olivier Allix (Cachan), Norman Fleck (Cambridge), Paul Steinmann (Kaiserslautern). There are currently 19 Euromech Fellows in Fluid Mechanics and 17 in Solid Mechanics.

\section{Concluding remarks}

There is no doubt that George Batchelor, through his initiative and his continuous commitment to the welfare of the Society, has left a permanent mark that will persist for 


\section{G. Batchelor and the founding of Euromech}

many years to come: rigorous and meticulous evaluation of colloquium, conference and award proposals, careful examination of the best course of action for the Society. Yet he was very successful in maintaining a friendly and casual atmosphere among those involved in the 'running' of Euromech, by keeping considerations of national pride and 'political' strategies at bay. Over the years, such features have been nurtured and participating in Euromech affairs remains a pleasurable and gratifying experience. The initiation and the development of a Society such as Euromech relied on the collective action of several outstanding individuals. The author has attempted to convey the collective nature of the enterprise by mentioning their implication explicitly. He apologises if some may have been inadvertently omitted.

Euromech has grown into a major actor in the exchange of scientific information, the establishment of personal contacts and the collaboration between scientists in Europe. This is due in large part to George Batchelor's visionary action.

Acknowledgements. The author (P.H.) is extremely grateful to H. Fernholz for his most comprehensive account of the history of Euromech from its foundation to 2000 (Fernholz 2010), the year of G. Batchelor's passing. Without the information contained in his book, the present article could not have been written. M. Okrouhlik (Prague) is warmly thanked for allowing P.H. to reproduce some of the photographs included in appendix 2 of Fernholz (2010). L. Lesshafft (LadHyX) is also acknowledged for his kind assistance in the final stages of this work.

Declaration of interests. The author reports no conflict of interest.

Author ORCIDs.

(D) Patrick Huerre http://orcid.org/0000-0001-6776-2825.

\section{REFERENCES}

Batchelor, G.K. \& KüChemann, D. 1964 Memorandum on European Mechanics Colloquia - Euromech. (07/12/1964).

Fernholz, H.H. 2010 The European Mechanics Society: From its Founding in 1964 to 2000. Euromech.

KüChemann, D. 2013 The Aerodynamic Design of Aircraft. AIAA Education Series. 